\title{
Optimization Parameter Design of SEPIC-Cuk Converter
}

\author{
M. K. R. Noor ${ }^{1}$, A. Ponniran ${ }^{1 *}$, M. A. Z. A. Rashid ${ }^{1}$, J. N. Jumadril ${ }^{1}$, A. A. \\ Bakar $^{1}$, K. S. Muhammad ${ }^{2}$, M. H. Yatim ${ }^{1}$ and A. N. Kasiran ${ }^{1}$
}

${ }^{1}$ Faculty of Electrical and Electronic Engineering,

Universiti Tun Hussein Onn Malaysia, 86400 Parit Raja, Johor, MALAYSIA

${ }^{2}$ Faculty of Electrical Engineering,

Universiti Teknologi MARA, 40450 Shah Alam, Selangor, MALAYSIA

1kkamilromainoor@gmail.com

1*asmarashid.ponniran@gmail.com

DOI: https://doi.org/10.30880/ijie. 2019.11.01.004

Received 15 March 2018; Accepted 18 November 2018; Available online 30 April 2019

\begin{abstract}
This paper discusses the optimization parameters design of combined SEPIC-Cuk converter based on SEPIC and Cuk operation for dual output voltage polarities. The SEPIC-Cuk converter is designed to be operated in continuous conduction mode, the selection of passive components, i.e., inductor and capacitor are based on the switching frequency, the duty cycle and inductor current ripple. The range of duty cycle for buck operation is $0<\mathrm{D}<0.5$, meanwhile for boost operation, the duty cycle range is $0.5<\mathrm{D}<1$. The simulation and experimental results show a good agreement. Thus, the designed parameters of the converter are confirmed. The finding shows that during buck operation, the output voltages are $+3.96 \mathrm{~V}$ and $-3.96 \mathrm{~V}$ with duty cycle of 0.25 when the output voltage is $12 \mathrm{~V}$. Meanwhile, during boost operation, the output voltages are $+36 \mathrm{~V}$ and $-36 \mathrm{~V}$ with the duty cycle of 0.75 when the output voltage is $12 \mathrm{~V}$.
\end{abstract}

Keywords: SEPIC-Cuk converter, DC-DC converter.

\section{Introduction}

In recent years, portable electronic equipment has advanced from a power converter and has the advantages of high efficiency, small in size and possess a wide input and output voltage ranges [1]-[6]. On the other hand, the conventional power converter could not operate in a wide operation range with high efficiency; especially when the step up and step down voltage conversion has to be achieved [7], [3], [8]. Besides, battery voltage decreases as the battery discharges and will lead to various difficulties if there is no voltage control. Therefore, the most effective method of regulating voltage through a circuit is by using a DC/DC converter. SEPIC-Cuk converter can be applied in a battery because the voltage can be stepped up or stepped down depending on the regulator's preferred output. For example, two outputs of single input voltage sources are useful in various cases such as electrical machines, multi voltage DC micro grids, solar energy systems, data communication and telecom power systems [9]-[11].

SEPIC and Cuk converters have a different type of structure in the SEPIC-Cuk converter, where the SEPIC converter produces positive output polarity while Cuk converter produces negative output polarity. Basically, a SEPIC and Cuk converter is a buck-boost converter that can act as Buck or Boost converter depending on its duty cycle [7], [9], [10], [12]. The unique feature of the converter is that it has one switch only with the dual output polarities. The PWM switching signal can be designed using FPGA as in [13] and [14]. 
This paper proposed a SEPIC-Cuk converter which can produce a regulated output voltage with positive and negative polarities. The output of this converter can be regulated by using a single switch which is PWM switching signal through FPGA board. The theoretical and simulation results have been verified and compared by a $50 \mathrm{~W}$ experimental prototype. In addition, the optimization parameters for the passive components are discussed in detail in this paper. The proposed converter has the following advantages: two different outputs polarities, regulated output DC voltage and minimum number of power switch.

\section{Principle of SEPIC-Cuk converter}

Single-ended primary-inductor converter (SEPIC) is a type of DC-DC converter that allows the stepping-up and stepping-down of output voltage. Fig. 1 shows the SEPIC part that requires a larger current across the inductor $L_{2}$, meanwhile the Cuk part requires a larger voltage across the capacitor $C_{2}$. The operation of SEPIC is the same as the conventional buck-boost converter, where the output voltage is always positive polarity. However, the Cuk has only negative output voltage with buck and boost operations.

A dual output voltage DC/DC converter consists of a combination of SEPIC-Cuk converter with their respective characteristics. When SEPIC-Cuk characteristics are compared, the converter will have the same voltage conversion ratio but different in polarities. The performance of SEPIC and Cuk combination converter can be analyzed in terms of the size of magnetic components, low input ripple and device stress.

However, when the duty cycle approaches one, the DC gain moves towards zero [15]. To determine the optimization of parameter, the minimum value of frequency need to be considered. When the duty cycle increases, the value of frequency decreases which resulting the ripple current on the inductor to decrease.

Fig. 2 shows the DC gain characteristics for the SEPIC-Cuk converter. This structure on Fig. 1 consists of buck and boost operation in which the buck operation has less than 0.5 duty cycle compared to the boost operation that has more than 0.5 duty cycle.

Fig. 3 shows the relationship between switching frequency and the duty cycle. It shows the boundary of CCM and DCM in terms of the minimum selection of switching frequency versus duty cycle. Besides, the appropriate inductance can be determined from the boundary of CCM and DCM. On the other hand, the middle point of duty cycle of buck and boost operation modes are 0.25 and 0.75 , respectively.

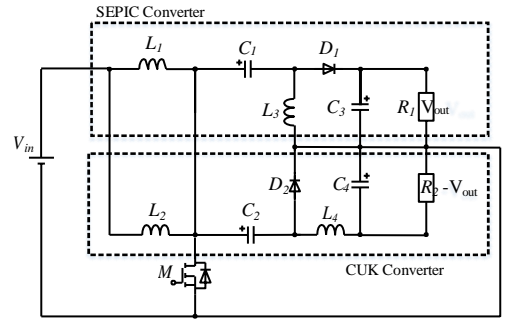

Fig. 1 - Circuit of SEPIC-Cuk converter [7]

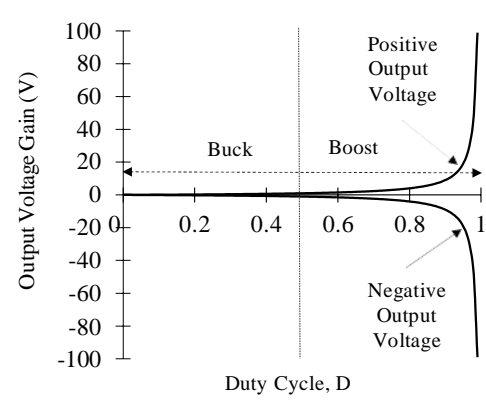

Fig. 2 - DC gain characteristics

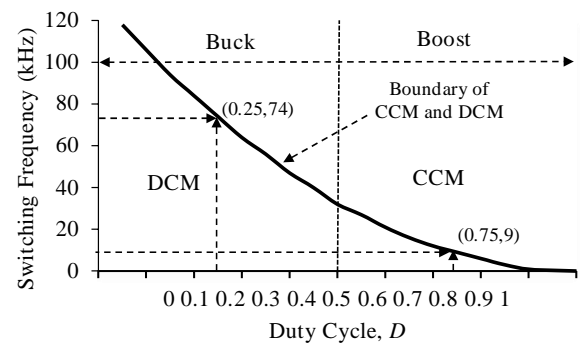

Fig. 3 - Boundary of CCM and DCM

\section{Operation of SEPIC-Cuk converter}

In topology [7], the circuit of combination SEPIC-Cuk converter is controlled by a single switch as shown in Fig. 1. This circuit can be divided into two operating modes.

Mode 1: The equivalent circuit of SEPIC-Cuk converter in mode 1 operation is shown in Fig. 4 (a). When the switch $\mathrm{M}$ is turned-ON, the energy is stored in $L_{l}$. Initially, $L_{l}$ is equivalent to two inductors $\left(2 L_{l}\right)$. At the same time, inductors $L_{2}$ and $L_{3}$ stored energy due to the discharge of $C_{1}$ and $C_{2}$. During this interval, the freewheeling diodes (D and $\mathrm{D}_{2}$ ) are turned-off and the power is supplied to the loads.

Mode 2: The equivalent circuit of SEPIC-Cuk converter in mode 2 operation is shown in Fig. 4 (b). When the switch $\mathrm{M}$ is turned-off, the inductors recharge the capacitors $C_{l}$ and $C_{2}$ through the freewheeling diodes and supply power to the loads. 


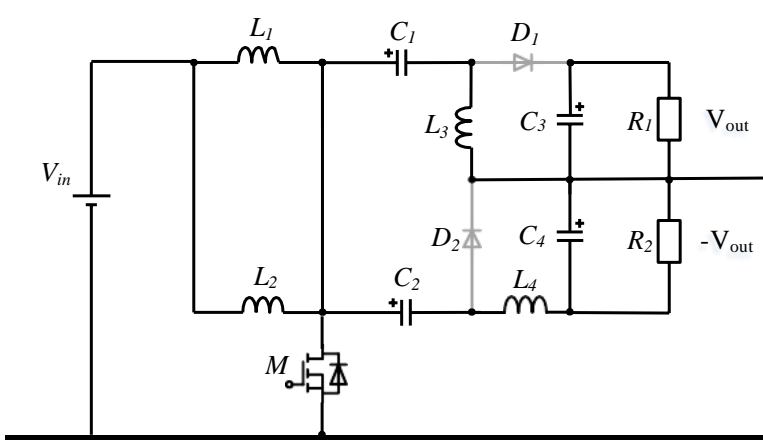

(a)

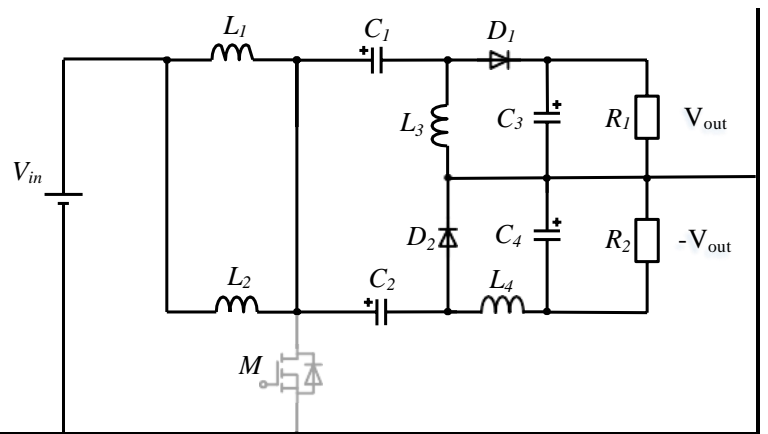

(b)

Fig. 4 - Equivalent circuit of SEPIC and CUK converters in (a) mode 1 and (b) mode 2 [7]

\section{SEPIC-Cuk Converter design parameter}

The main function of SEPIC-Cuk converter is to increase and decrease the output voltage with a different polarity. The initial specification is considered in order to determine the parameters of the converter. The converter specifications are shown in Table 1.

Table 1 - Initial specification of SEPIC and CUK converters parameters

\begin{tabular}{|c|c|c|c|c|c|}
\hline Parameters & \multicolumn{5}{|c|}{ Values } \\
\hline Input Voltage, $V_{i n}$ & \multicolumn{5}{|c|}{$12 \mathrm{~V}$} \\
\hline Switching Frequency, $F_{S W}$ & \multicolumn{5}{|c|}{$50 \mathrm{kHz}$} \\
\hline Output Resistor, $R$ & \multicolumn{5}{|c|}{$200 \Omega$} \\
\hline Duty Cycle, $D$ & $25 \%$ & $40 \%$ & $50 \%$ & $60 \%$ & $75 \%$ \\
\hline Boost ratio, $\beta$ & 0.33 & 0.67 & 1.00 & 1.50 & 3.0 \\
\hline
\end{tabular}

\subsection{Output Voltage}

Based on the input voltage specification, Table 1, the output voltage of SEPIC and Cuk can be expressed in Eqn. (1) and Eqn. (2) respectively as follows:

$$
\begin{aligned}
& \text { SEPIC: } V_{1}=\frac{D \cdot V_{i n}}{1-D} \\
& \text { CUK: } V_{2}=-\frac{D \cdot V_{i n}}{1-D}
\end{aligned}
$$

\subsection{Inductors Selection}

Next, the input inductors $\left(L_{1}\right.$ and $\left.L_{2}\right)$ and other inductors $\left(L_{3}\right.$ and $\left.L_{4}\right)$ can be expressed in Eqn. (3). Theoretically, the larger the inductance, the lower the inductor current ripple. However, the appropriate selection of the inductance is an important aspect to be considered.

$$
L_{x}=\frac{V_{i n} \cdot D}{\Delta I \cdot L_{x} \cdot f_{s}}
$$

where, $L x=L_{1}=L_{2}=L_{3}=L_{4}$

\subsection{Link Capacitor Selection}

The third step to calculate the link capacitors $\left(C_{l}\right.$ and $\left.C_{2}\right)$, Eqn. (4). The role of the link capacitor is to transfer the energy to the output side.

$$
\begin{gathered}
C_{x}=\frac{I_{i n}(1-D)}{\Delta V \cdot C_{x} \cdot f} \\
\text { where, } C_{x}=C_{l}=C_{2}
\end{gathered}
$$




\subsection{Output Capacitor Selection}

The fourth step is the estimation of the output capacitors $\left(C_{3}\right.$ and $\left.C_{4}\right)$. The output capacitors such that the ripple at the output voltage is less than $1 \%$ of the DC output voltage. Therefore, the output voltage ripple can be expressed as follows:

$$
\Delta V_{\text {out }}=\frac{V_{\text {out }}(1-D)}{8 \cdot R \cdot C} T_{s}^{2}
$$

\subsection{Parameters Estimation}

After all the parameters are determined, the SEPIC-Cuk converter specifications are listed as shown in Table 2. The output voltage depends on the duty cycle.

Table 2 - SEPIC and CUK converters calculation parameters

\begin{tabular}{|c|c|c|c|c|c|}
\hline Parameters & \multicolumn{5}{|c|}{ Values } \\
\hline Input Voltage, $V_{i n}$ & \multicolumn{5}{|c|}{$12 \mathrm{~V}$} \\
\hline Switching Frequency, $F_{S W}$ & \multicolumn{5}{|c|}{$50 \mathrm{kHz}$} \\
\hline Output Resistor, $R$ & \multicolumn{5}{|c|}{$200 \Omega$} \\
\hline Duty Cycle, $D$ & $25 \%$ & $40 \%$ & $50 \%$ & $60 \%$ & $75 \%$ \\
\hline Boost ratio, $\beta$ & $\underline{0.33}$ & $\underline{0.67}$ & 1.00 & 1.50 & 3.0 \\
\hline
\end{tabular}

\section{Experimental Results}

Table 3 shows the output voltage based on the duty cycle of the SEPIC-Cuk converter. It can be observed that for the calculation results, the estimated output voltages are based on the ideal condition. Due to the parasitic elements on the non-ideal components, there are errors between the design values and the experimental results. But the errors are small and can be considered acceptable. Thus, all the results between calculation, simulation and experiment are in a good agreement, Table 3.

Figs. 5 (a), (b), (c), (d), and (e) shows the output voltage waveform of the SEPIC-Cuk converter with several duty cycles, i.e., $25 \%, 40 \%, 50 \%, 60 \%$ and $75 \%$. The switching frequency and the input voltage are fixed at $50 \mathrm{kHz}$ and 12 $\mathrm{V}$, respectively for all the duty cycle operations. The switching frequency of $50 \mathrm{kHz}$ is selected for CCM operation and the values for all the inductances are fixed at $3.3 \mathrm{mH}$. The operation for buck and boost of the SEPIC-Cuk converter are verified by these experimental results. Thus, the design parameters of the converter are confirmed.

Table 3 - All result output voltage of SEPIC-Cuk converter

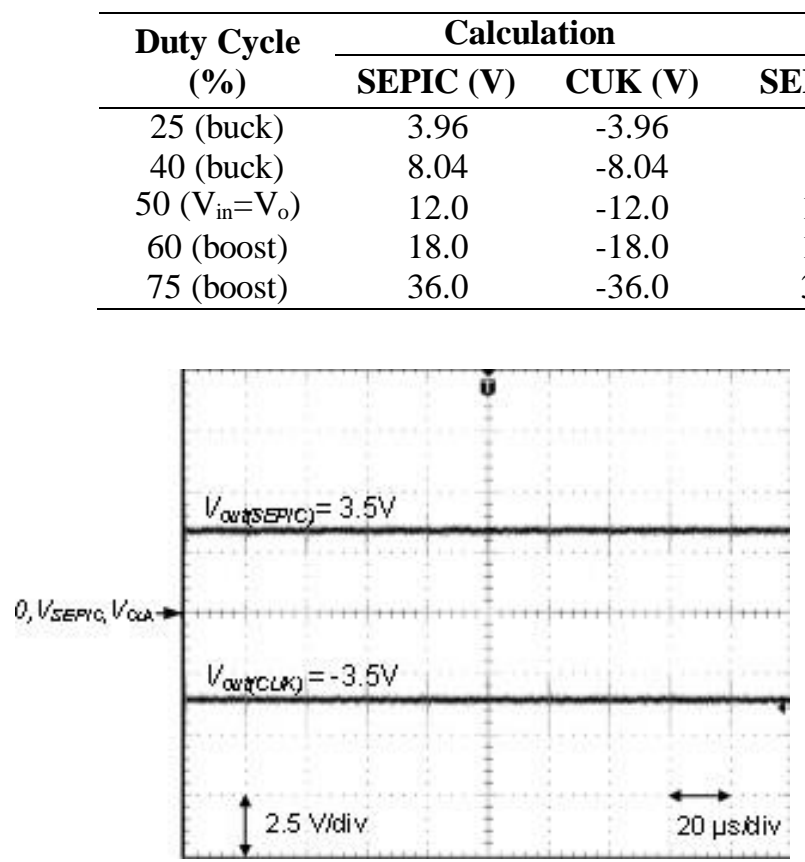

(a)

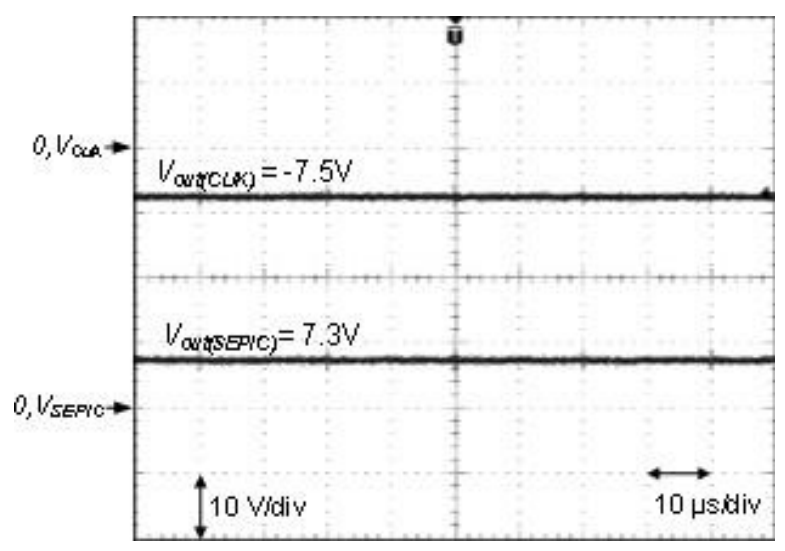

(b) 


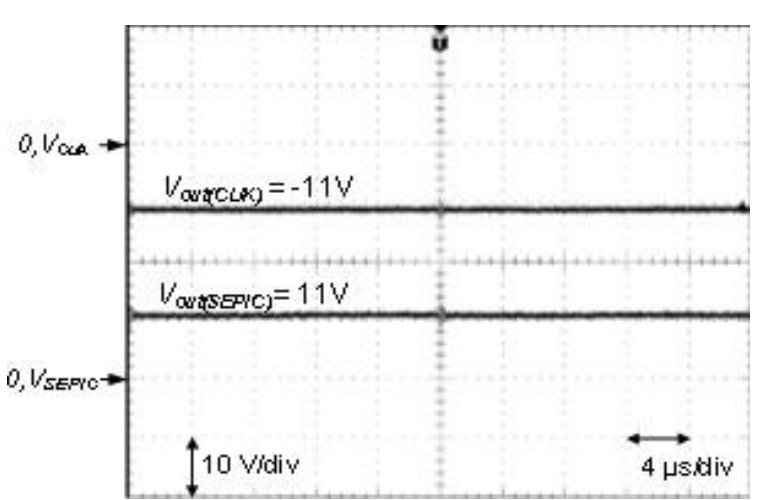

(c)

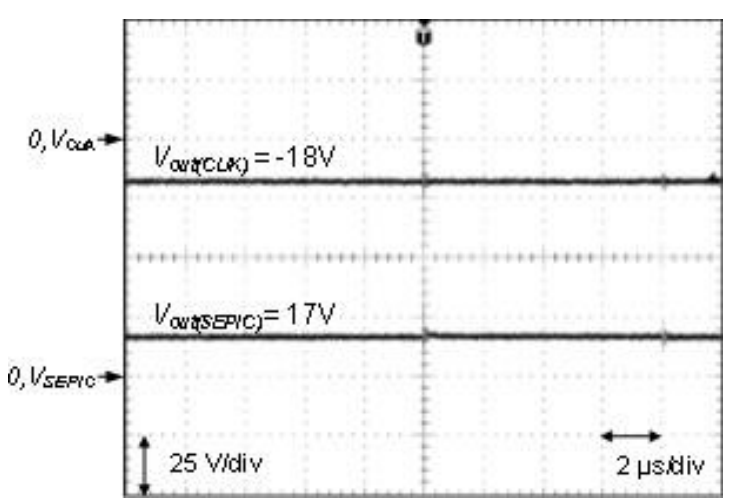

(d)

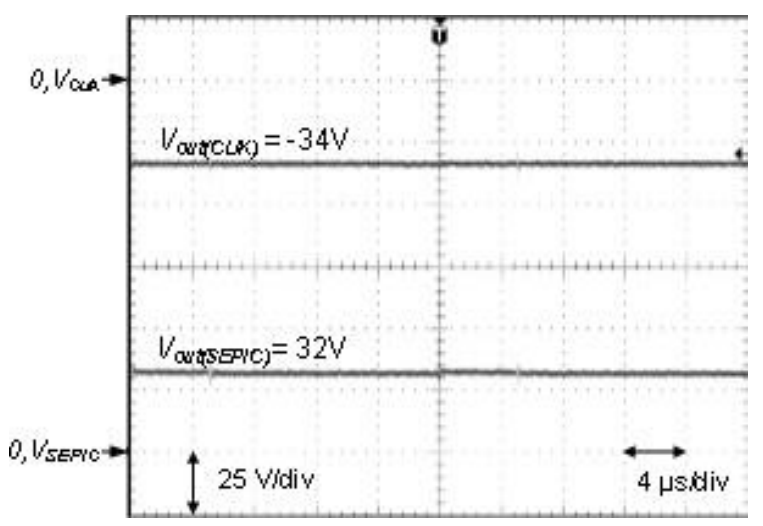

(e)

Fig. 5 - The output voltage of SEPIC-Cuk converter with duty cycle (a) $25 \%$ (b) $40 \%$ (c) $50 \%$ (d) $60 \%$ (e) $75 \%$

\section{Conclusion}

This paper discussed the designed parameters and operation of the SEPIC-Cuk converter with dual polarities of the output voltages and single switch consideration. In addition, structure uses only single switch (MOSFET) in order to control both circuits, positive (SEPIC) and negative (Cuk) polarities. Based on the experimental results, the designed parameters of the converter have been confirmed.

\section{Acknowledgement}

The authors would like to show gratitude to Universiti Tun Hussein Onn Malaysia (UTHM) from the financial support by GPPS Vot.H027 and Research Fund, UTHM

\section{References}

[1] A. Ponniran, K. Orikawa, and J. I. Itoh, "Modular multi-stage Marx topology for high boost ratio DC/DC converter in HVDC," in INTELEC, International Telecommunications Energy Conference (Proceedings), 2016, vol. 2016-Septe, pp. 1-6.

[2] A. Bin Ponniran, K. Orikawa, and J. I. Itoh, "Interleaved high boost ratio Marx topology DC-DC converter," in 2015 IEEE 2nd International Future Energy Electronics Conference, IFEEC 2015, 2015.

[3] A. Bin Ponniran, K. Orikawa, and J. Itoh, "Fundamental Operation of Marx Topology for High Boost Ratio DCDC Converter," IEEJ J. Ind. Appl., vol. 5, no. 4, pp. 329-338, 2016.

[4] S. Zeljkovic, T. Reiter, and D. Gerling, "Single-Stage Reconfigurable DC/DC Converter for Wide Input Voltage Range Operation in (H)EVs," IEEJ J. Ind. Appl., vol. 4, no. 4, pp. 424-433, 2015.

[5] J. MingGuo, A. Parastar, and S. Jul-Ki, "High efficiency multilevel flying-capacitor DC/DC converter for distributed generation applications," in Energy Conversion Congress and Exposition (ECCE), 2014 IEEE, 2014, pp. 4269-4275.

[6] C. Abraham, R. Rakhee, and B. R. Jose, "A Multiple Input Multiple Output Switched Capacitor DC-DC Converter with Reduced Switch Count," in Electronic System Design (ISED), 2014 Fifth International Symposium on, 2014, pp. 104-108. 
[7] A. Shahul, P. A. P. Oommen, and P. B. Cherian, "Self Lifted SEPIC-Cuk Combination Converter," vol. 3, no. 2, pp. 36-43, 2016.

[8] A. Bin Ponniran, S. Member, K. Orikawa, and M. Jun-ichi Itoh, "Minimization of Passive Components in Multilevel Flying Capacitor DC-DC Converter," IEEJ J. Ind. Appl., vol. 5, no. 1, pp. 10-11, 2015.

[9] M. B. Ferrera, S. P. Litrán, E. D. Aranda, and J. M. A. Márquez, "A Converter for Bipolar DC Link Based on SEPIC-Cuk Combination,” IEEE Trans. Power Electron., vol. 30, no. 12, pp. 6483-6487, 2015.

[10] J. Marjani, A. Imani, A. Hekmati, and E. Afjei, "A new dual output DC-DC converter based on SEPIC and Cuk converters," in 2016 International Symposium on Power Electronics, Electrical Drives, Automation and Motion (SPEEDAM), 2016, pp. 946-950.

[11] A. Ponniran, K. Orikawa, and J. i. Itoh, "Modular multi-stage Marx topology for high boost ratio DC/DC converter in HVDC," in 2015 IEEE International Telecommunications Energy Conference (INTELEC), 2015, pp. $1-6$.

[12] Y. Berkovich and B. Axelrod, "Switched-coupled inductor cell for DC-DC converters with very large conversion ratio," Power Electron. IET, vol. 4, no. 3, pp. 309-315, 2011.

[13] A. A. A. Bakar, W. M. M. Utomo, S. A. A. Zulkifli, E. Sulaiman, M. Z. Z. Ahmad, and M. Jenal, "DC-DC Interleaved Boost Converter using FPGA," in IEEE Conference on Clean Energy and Technology, 2013, pp. 97100.

[14] A.A. Bakar, MU Wahyu, T Taufik, S Aizam, M Yonis and Jumadril, "Analog to Digital Converter for DC to DC Boost Converter with Constant Output Voltage," in The 3rd International Conference on Computer Engineering and Mathematical Sciences (ICCEMS 2014), 2015, no. December 2014, pp. 800-804.

[15] A. Shahul, P. A. P. Oommen, and P. B. Cherian, "Self Lifted SEPIC-Cuk Combination Converter," vol. 3, no. 2, pp. 36-43, 2016.

[16] Y. Ishizuka, S. Nagata, M. Takasaki, and T. Hirose, "Static Characteristic Analysis of Proposed Bi-Directional Dual Active Bridge DC-DC Converter,” IEEJ J. Ind. Appl., vol. 4, no. 5, pp. 602-610, 2015. 